\title{
Right Ventricular Outflow Tract Repair with a Cardiac Biologic Scaffold
}

\author{
John M. Wainwright ${ }^{a}$ Ryotaro Hashizume ${ }^{a}$ Kazuro L. Fujimoto ${ }^{a}$ \\ Nathaniel T. Remlinger ${ }^{a} \quad$ Colin Pesyna ${ }^{a} \quad$ William R. Wagner $^{a} \quad$ Kimimasa Tobita $^{a}$ b \\ Thomas W. Gilbert ${ }^{a, c}$ Stephen F. Badylak ${ }^{a}$ \\ ${ }^{a}$ Department of Surgery, McGowan Institute for Regenerative Medicine, University of Pittsburgh, and Departments \\ of ${ }^{b}$ Developmental Biology and ${ }^{c}$ Cardiothoracic Surgery, Children's Hospital of Pittsburgh, University of Pittsburgh \\ Medical Center, Pittsburgh, Pa., USA
}

\section{Key Words}

Heart defects, congenital · Tissue engineering $\cdot$ Surgery •

Myocardium $\cdot$ Remodeling

\begin{abstract}
Background: Surgical reconstruction of congenital heart defects is often limited by the nonresorbable material used to approximate normal anatomy. In contrast, biologic scaffold materials composed of resorbable non-cross-linked extracellular matrix (ECM) have been used for tissue reconstruction of multiple organs and are replaced by host tissue.
\end{abstract}

Preparation of whole organ ECM by decellularization through vascular perfusion can maintain much of the native threedimensional (3D) structure, strength, and tissue-specific composition. A 3D cardiac ECM (C-ECM) biologic scaffold material would logically have structural and functional advantages over materials such as Dacron ${ }^{\mathrm{TM}}$ for myocardial repair, but the in vivo remodeling characteristics of C-ECM have not been investigated to date. Methods and Results: A porcine C-ECM patch or Dacron patch was used to reconstruct a full-thickness right ventricular outflow tract (RVOT) defect in a rat model with end points of structural remodeling function at 16 weeks. The Dacron patch was encapsu-

Abbreviations used in this paper

\begin{tabular}{llll}
\hline 3D & 3-dimensional & LV & left ventricle \\
b-FGF & basic fibroblast growth factor & RV & right ventricle \\
BSA & bovine serum albumin & RVOT & scantricular outflow tract \\
C-ECM & cardiac extracellular matrix & SEM electron microscopy \\
CHD & congenital heart defects & SIS & small intestinal submucosa \\
DAPI & $4^{\prime}$ 6-diamidino-2-phenylindole & SMMHCII & smooth muscle myosin heavy chain 2 \\
ECM & extracellular matrix & TGF- $\beta$ & transforming growth factor- $\beta$ \\
H\&E & hematoxylin and eosin & UBM & urinary bladder matrix \\
IF & immunofluorescent & VEGF & vascular endothelial growth factor \\
islet1+ & islet 1-positive & vWF & von Willebrand factor \\
\hline
\end{tabular}

\section{KARGER}

() 2011 S. Karger AG, Basel

Fax +4161306 1234

E-Mail karger@karger.ch

www.karger.com
Accessible online at: www.karger.com/cto
Dr. Stephen F. Badylak

McGowan Institute for Regenerative Medicine, University of Pittsburgh

450 Technology Drive, Suite 300

Pittsburgh, PA 15219 (USA)

Tel. +1 412624 5253, E-Mail badylaks@upmc.edu 
lated by dense fibrous tissue and showed little cellular infiltration. Echocardiographic analysis showed that the right ventricle of the hearts patched with Dacron were dilated at 16 weeks compared to presurgery baseline values. The CECM patch remodeled into dense, cellular connective tissue with scattered small islands of cardiomyocytes. The hearts patched with C-ECM showed no difference in the size or function of the ventricles as compared to baseline values at both 4 and 16 weeks. Conclusions: The C-ECM patch was associated with better functional and histomorphological outcomes compared to the Dacron patch in this rat model of RVOT reconstruction.

Copyright $\odot 2011$ S. Karger AG, Basel

\section{Introduction}

Approximately 3 in 1,000 infants require corrective surgery for congenital heart defects (CHD) within the first year of life [Lloyd-Jones et al., 2009]. Currently available homografts and synthetic biomaterials for surgical reconstruction are typically associated with rejection, stenosis, aneurysm formation, and calcification [Sousa Uva et al., 1994; Rajani et al., 1998; Breymann et al., 2009; Hickey et al., 2009; Konuma et al., 2009]. Even if corrective surgery is not required for the complications listed above, additional surgery may be required to accommodate the growth of the patient since available nonresorbable materials do not change size or shape over time as the surrounding tissue develops proportionally with the patient [Sousa Uva et al., 1994; Hickey et al., 2009]. In contrast, non-cross-linked biologic scaffold materials composed of extracellular matrix (ECM) are typically degradable, associated with a robust host cellular response and deposition of neomatrix that does remodel appropriately in response to host factors such as growth or change in mechanical loading. Use of such biologic scaffold materials has been shown to promote a site-appropriate constructive remodeling response of numerous tissue types including the heart [Badylak et al., 2005; Ota et al., 2007; Gilbert et al., 2008; Kelly et al., 2009].

Since the surface characteristics [Brown et al., 2010], mechanical properties [Freytes et al., 2006, 2008], and ultrastructure [Brown et al., 2006; Wainwright et al., 2010] of the ECM harvested from each tissue are distinct and unique, it is logical and plausible that a cardiac ECM (CECM) material would be best suited to facilitate the constructive remodeling of cardiac tissue. C-ECM has been produced by several laboratories and has shown multiple structural and functional benefits over synthetic materi- als [Ott et al., 2008; Singelyn et al., 2009; Eitan et al., 2010; Wainwright et al., 2010]. A detailed method to decellularize an intact porcine heart in less than $10 \mathrm{~h}$ has been described [Wainwright et al., 2010]. Whole heart C-ECM in an in vitro perfusion system has been shown to support contractile cardiomyocytes that generate aortic pressure [Ott et al., 2008]. Singelyn et al. [2009] showed angiogenesis after injection of a gel form of C-ECM in a noninfarct cardiac rat model. While each of these studies showed the potential benefits of C-ECM, none compared C-ECM to a clinically used material for ventricular reconstruction.

The objective of the present study was to assess the ability of C-ECM as a patch material to replace and remodel a full-thickness right ventricular outflow tract (RVOT) defect in a Lewis rat model. Results were compared to those of a Dacron ${ }^{\mathrm{TM}}$ patch which is commonly used for myocardial reconstruction.

\section{Methods}

Overview of Experimental Design

C-ECM was compared to Dacron for myocardial reconstruction in a right ventricular defect model. Specifically, a 6-mm diameter C-ECM patch and Dacron patch were used to replace a full-thickness RVOT defect in a rat model. The primary end points of the study were histomorphology and echocardiographic assessment. Eleven rats were included in each group and 8 of these animals were sacrificed at 16 weeks postsurgery. One additional rat from each group was sacrificed at 2,4 , and 8 weeks to obtain a preliminary evaluation of the remodeling process over time. Cell phenotype and morphology were evaluated at all time points using immunohistochemistry and immunolabeling techniques. Heart dimensions and function were quantified using echocardiography prior to surgery and at 4 and 16 weeks postsurgery.

\section{Preparation of C-ECM}

Intact porcine hearts were perfusion decellularized to produce a C-ECM biological scaffold as previously described [Wainwright et al., 2010]. Briefly, porcine hearts were obtained immediately following euthanasia and frozen at $-80^{\circ} \mathrm{C}$ for at least $16 \mathrm{~h}$ and thawed. The aorta was cannulated and alternately perfused with type 1 reagent grade (type 1) water and $2 \times \mathrm{PBS}$ at 1 liter/min for 15 min each. Serial perfusion of $0.02 \%$ trypsin $/ 0.05 \%$ EDTA $/ 0.05 \%$ $\mathrm{NaN}_{3}$ at $37^{\circ} \mathrm{C}, 3 \%$ Triton X-100/0.05\% EDTA $/ 0.05 \% \mathrm{NaN}_{3}$, and $4 \%$ deoxycholic acid was conducted (each for $2 \mathrm{~h}$ at approximately 1.2 liters $/ \mathrm{min}$ ). Finally, the heart was perfused with $0.1 \%$ peracetic acid/4\% EtOH at 1.7 liters/min for $1 \mathrm{~h}$. After each chemical solution, type 1 water and $2 \times$ PBS were flushed through the heart to aid in cell lysis and the removal of cellular debris and chemical residues. The free wall of the decellularized porcine right ventricle (RV) was lyophilized and 6-mm-diameter patches were cut using a tissue punch. The 6-mm Dacron patch was cut from Bard ${ }^{\circledR}$ DeBakey ${ }^{\circledR}$ Woven Fabric (Bard Peripheral Vascular, Inc., Tempe, Ariz., USA) (fig. 1). The average C-ECM patch thickness was 2.5 

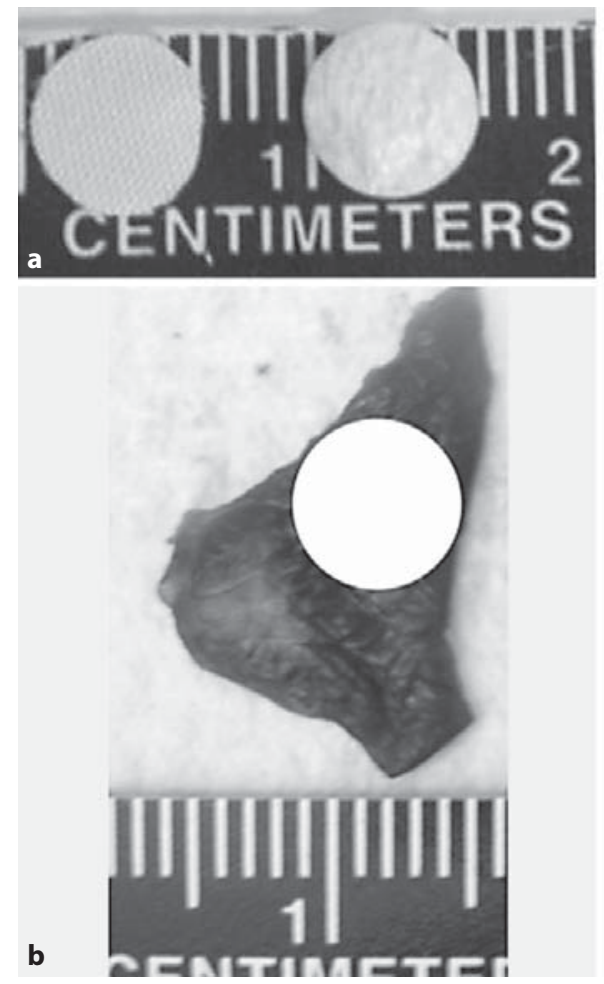
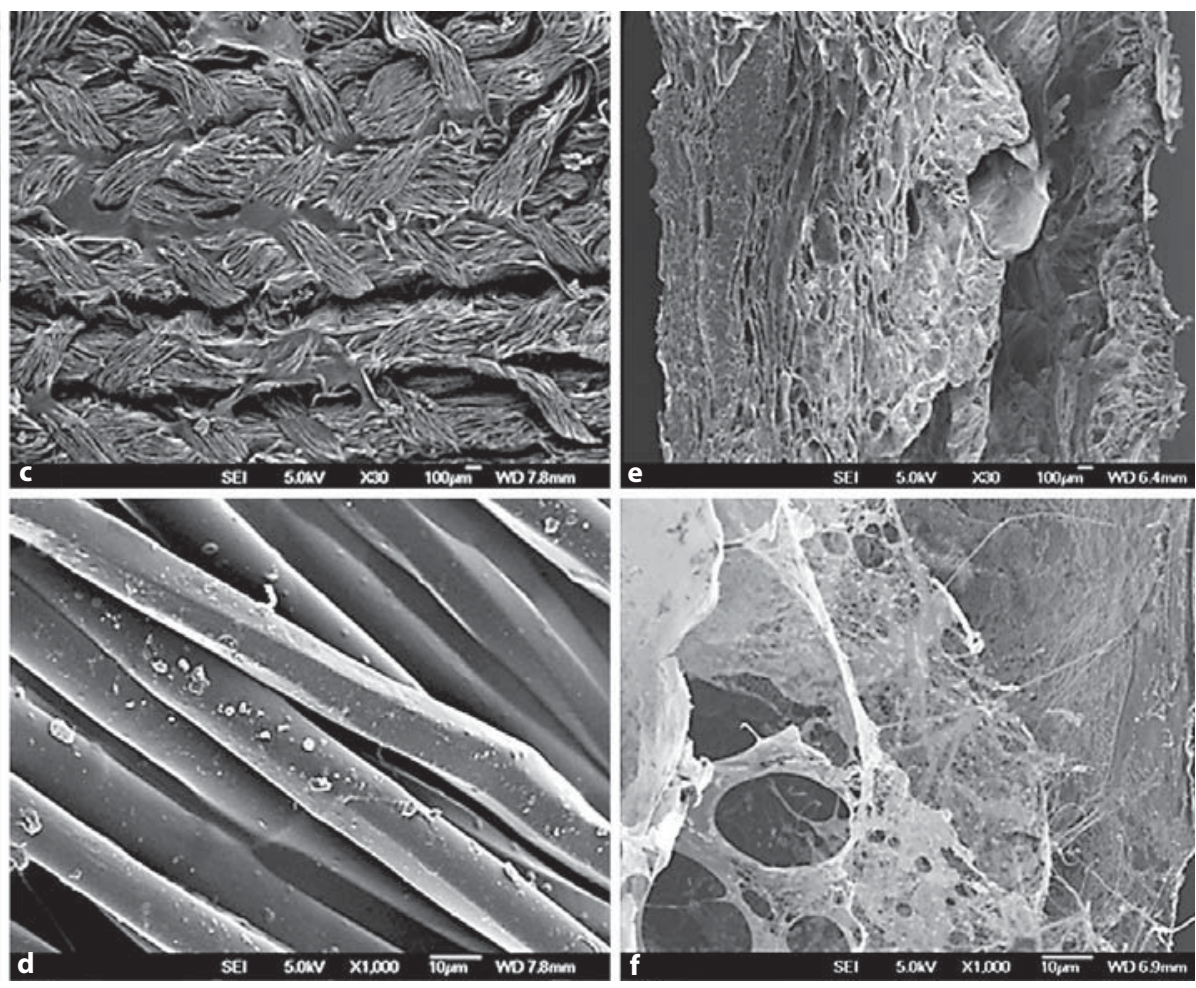

Fig. 1. Dacron and C-ECM patches. a Macroscopic photo of the patches. Dacron is on the left and C-ECM is on the right. $\mathbf{b}$ Approximate placement of a $6-\mathrm{mm}$ patch in the RVOT shown on excised RV free wall. SEM of Dacron: $\times 30(\mathbf{c})$ and $\times 1,000$ (d). SEM of C-ECM with endocardium on the right side: $\times 30(\mathbf{e})$ and $\times 1,000(\mathbf{f})$.

$\mathrm{mm}$ and the Dacron patch was $0.25 \mathrm{~mm}$ thick. All patches were packaged in sterilization pouches and terminally sterilized using ethylene oxide (EO gas sterilizer Series 3 Plus; Anderson Products, Haw River, N.C., USA). The cellular content (i.e. decellularization efficacy) of porcine heart samples was assessed using three criteria: (1) the absence of visible nuclear material on hematoxylin and eosin (H\&E)-stained and 4',6-diamidino-2-phenylindole (DAPI)-stained sections, (2) a Quant-iT PicoGreen assay (Invitrogen, Carlsbad, Calif., USA) for quantification of double-stranded DNA, and (3) evaluation of a $2 \%$ agarose gel to determine the size of the remaining DNA fragments [Gilbert et al., 2009; Crapo et al., 2011].

\section{RVOT Surgical Procedure}

Adult female syngeneic Lewis rats (Harlan Sprague Dawley, Inc., Indianapolis, Ind., USA) weighing 175-200 g were used for the RVOT replacement procedure as previously described [Fujimoto et al., 2007]. Briefly, a surgical plane of anesthesia was obtained using isoflurane (approximately $2.5 \%$ ) in oxygen. The animals were intubated with a 16-gauge catheter and respiration maintained at 60 cycles $/ \mathrm{min}$ and a tidal volume of $1.5 \mathrm{ml}$. Using aseptic techniques with sterile instruments, the skin of the chest was sterilized with povidone-iodine solution and the heart was exposed through a median sternotomy. A purse string suture with a diameter slightly larger than $6.0 \mathrm{~mm}$ was placed in the free wall of the RVOT with Surgipro II 7-0 polypropylene sutures (Covi- dien, Mansfield, Mass., USA). Both ends of the suture were passed through a 22-gauge plastic vascular cannulae, which was used as a tourniquet. The tourniquet was tightened and the distended part of the RVOT wall inside the purse string suture was resected. The tourniquet was briefly released to determine whether massive bleeding occurred, which indicated that a transmural defect had been created in the RVOT. A 6-mm C-ECM or Dacron patch was sutured along the margin of the purse string suture with 7-0 polypropylene over-and-over sutures to cover the defect in the RVOT. After completion of suturing, the tourniquet was released and the purse string suture was removed. After the expansion of lungs using positive end-expiratory pressure, the sternum was closed parasternally with four interrupted Surgipro 5-0 polypropylene sutures (Covidien). The muscle layer and skin were closed with Polysorb 4-0 absorbable sutures (Covidien). The first 3 days after surgery, buprenorphine $(0.5 \mathrm{mg} / \mathrm{kg})$ analgesia and cefuroxime $(100 \mathrm{mg} / \mathrm{kg})$ antibiotic were administered twice a day subcutaneously and intramuscularly, respectively. One animal in each group was sacrificed at 2, 4 , and 8 weeks postsurgery and 8 animals from each group were sacrificed at 16 weeks postsurgery. At the time of sacrifice, animals were anesthetized by inhalation of isoflurane (5\%) in oxygen. Cardiac arrest solution $(68 \mathrm{mM} \mathrm{NaCl}$, $60 \mathrm{mM} \mathrm{KCl}, 36 \mathrm{~mm} \mathrm{NaHCO}_{3}, 2.0 \mathrm{mM} \mathrm{MgCl}_{2}, 1.4 \mathrm{mM} \mathrm{Na}_{2} \mathrm{SO}_{4}, 11$ $\mathrm{mM}$ dextrose, $30 \mathrm{~mm}$ butanedione monoxime, and 10,000 U/1 heparin) was administered intravenously and hearts were excised after death was confirmed. The research protocol followed the 

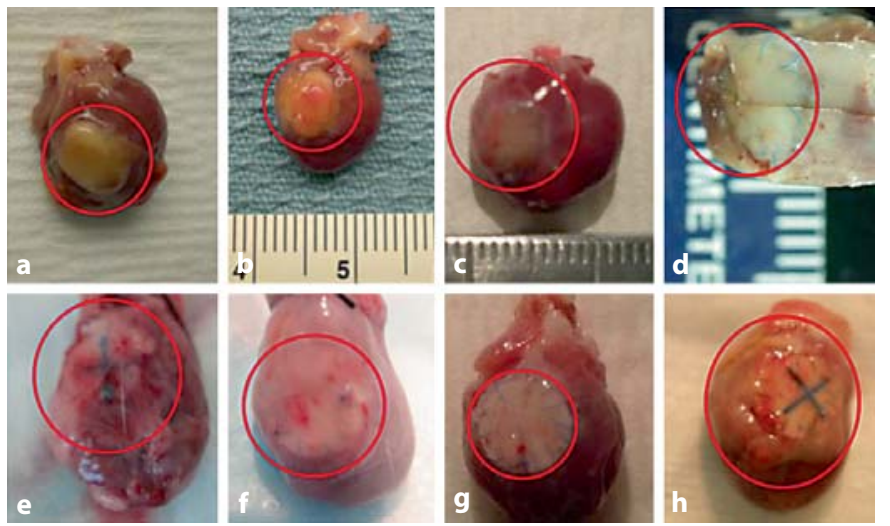

Fig. 2. Macroscopic images of the rat heart with the patched area at $2,4,8$, and 16 weeks postsurgery are enclosed in red ovals. The C-ECM patch decreased in thickness as it remodeled. Fibrous adhesions can be seen at 2 and 4 weeks on the Dacron-patched hearts. The adhesions were removed from the hearts at the later time points so that the patch could be better visualized. C-ECM at $2(\mathbf{a}), 4(\mathbf{b}), 8(\mathbf{c})$, and 16 weeks (d) after fixation. Dacron at $2(\mathbf{e})$, $4(\mathbf{f}), 8(\mathbf{g})$, and 16 weeks (h).

National Institutes of Health (NIH) guidelines and was approved by the Institutional Animal Care and Use Committee of the University of Pittsburgh.

\section{Immunohistochemistry and Immunolabeling Methods}

The hearts were fixed in $4 \%$ paraformaldehyde for $20 \mathrm{~min}$ followed by rinsing in PBS. The hearts were then placed in a $30 \%$ sucrose solution for at least $16 \mathrm{~h}$. Hearts were bisected along the short axis midway through the patch with a razor and placed in optimal cutting temperature solution (Sakura Finetek USA, Inc., Torrance, Calif., USA). Five-micrometer-thick frozen sections were cut for mounting, staining, and histological evaluation. Masson's trichrome stain was used to visualize muscle, fibrous tissue, and nuclei using a Nikon ${ }^{\mathrm{TM}} \mathrm{E} 600$ microscope (Nikon Instruments, Inc., Melville, N.Y., USA). The von Kossa stain was used to visualize calcification. Monoclonal anti- $\alpha$-actinin (sarcomeric) antibody (1:200; Sigma-Aldrich, St. Louis, Mo., USA) and cardiac troponin T antibody (1:100; Abcam, Cambridge, Mass., USA) were used to label cardiomyocytes. von Willebrand factor (vWF) antibody (1:100; Abcam) was used to identify endothelial cells. Smooth muscle myosin heavy chain 2 (SMMHCII) antibody (1:75; Abcam) was used to label smooth muscle cells. Connexin 43/GJA1 antibody (1:200; Abcam) was used to visualize gap junctions. All primary antibodies were incubated for $2 \mathrm{~h}$ at room temperature in $1 \%$ bovine serum albumin (BSA) followed by five 1\% BSA washes. All Alexa Fluor secondary antibodies (Life Technologies, Carlsbad, Calif., USA) were used at a concentration of 1:200 in 1\% BSA for $2 \mathrm{~h}$ at room temperature followed by five 1\% BSA washes. Nuclei were counterstained with DAPI and/or DRAQ5 ${ }^{\text {TM }}$ (Biostatus Limited, Shepshed, UK). Immunofluorescent (IF) slides were imaged on a Leica DMI 4000B (Leica Microsystems, Inc., Buffalo Grove, Ill., USA) or Fluoview 1000 (Olympus America, Center Valley, Pa., USA) confocal microscope.

\section{Echocardiographic Analysis}

Echocardiographic measurements were obtained preoperatively and at 4 and 16 weeks postoperatively. Animals underwent isoflurane anesthesia (1.5\% isoflurane with $100 \%$ oxygen gas inhalation through a nose cone). When the anesthesia plane was established, B-mode, M-mode, and color flow mapping echocardiography was performed (Philips HD11 system; Philips, Andover, Mass., USA). We visualized left ventricle (LV) short and long axis views and RV outflow to pulmonary valve short and long axis views. RV and LV minimum and maximum diameters were measured using M-mode echocardiography. Acquired images were converted to Dicom image files and the cavity diameters and LV fractional shortening were calculated using Image $J$ software (NIH, Bethesda, Md., USA).

\section{Statistical Analysis}

A repeated measures ANOVA with Tukey's post hoc analysis was performed to determine whether differences existed between the preoperative, the 4 weeks postoperative, and the 16 weeks postoperative echocardiographic values within each patch group. $\mathrm{p}=0.05$ was considered statistically significant $\left(\right.$ Minitab $^{\circledR}$ version 15.1.1.0; Minitab, State College, Pa., USA).

\section{Results}

\section{Surgical Observations}

Macroscopic and scanning electron microscopy (SEM) images of the patches can be seen in figure 1 . The $6-\mathrm{mm}$ patches replaced approximately $25 \%$ of the RV free wall (fig. 1b). At the time of implantation, it took longer to achieve hemostasis with the Dacron patch than with the C-ECM patch. There was one postoperative death in both the Dacron and C-ECM group. Due to the 2.5-mm thickness of the C-ECM patch, it protruded above the epicardial surface of the RV at implantation, but the difference was minimal as remodeling progressed to the time point of 16 weeks (fig. 2). There were dense fibrous adhesions on the epicardial surface on almost all of the Dacronpatched hearts that were adhered to the sternum, but there were fewer adhesions on the C-ECM-patched hearts (fig. 2).

\section{Immunohistochemistry Analysis}

The Dacron material successfully patched the RVOT defect but was encapsulated by fibrous tissue, and there were very few cells that infiltrated the polyester weave of the Dacron patch. There were minimal histologic differences in the patched region between the time points of 2 , 4, 8, and 16 weeks (fig. 3). The connective tissue surrounding the Dacron patch had a continuous endothelial layer on the endocardial surface as shown by the positive staining for vWF. There were few endothelial cells and no 

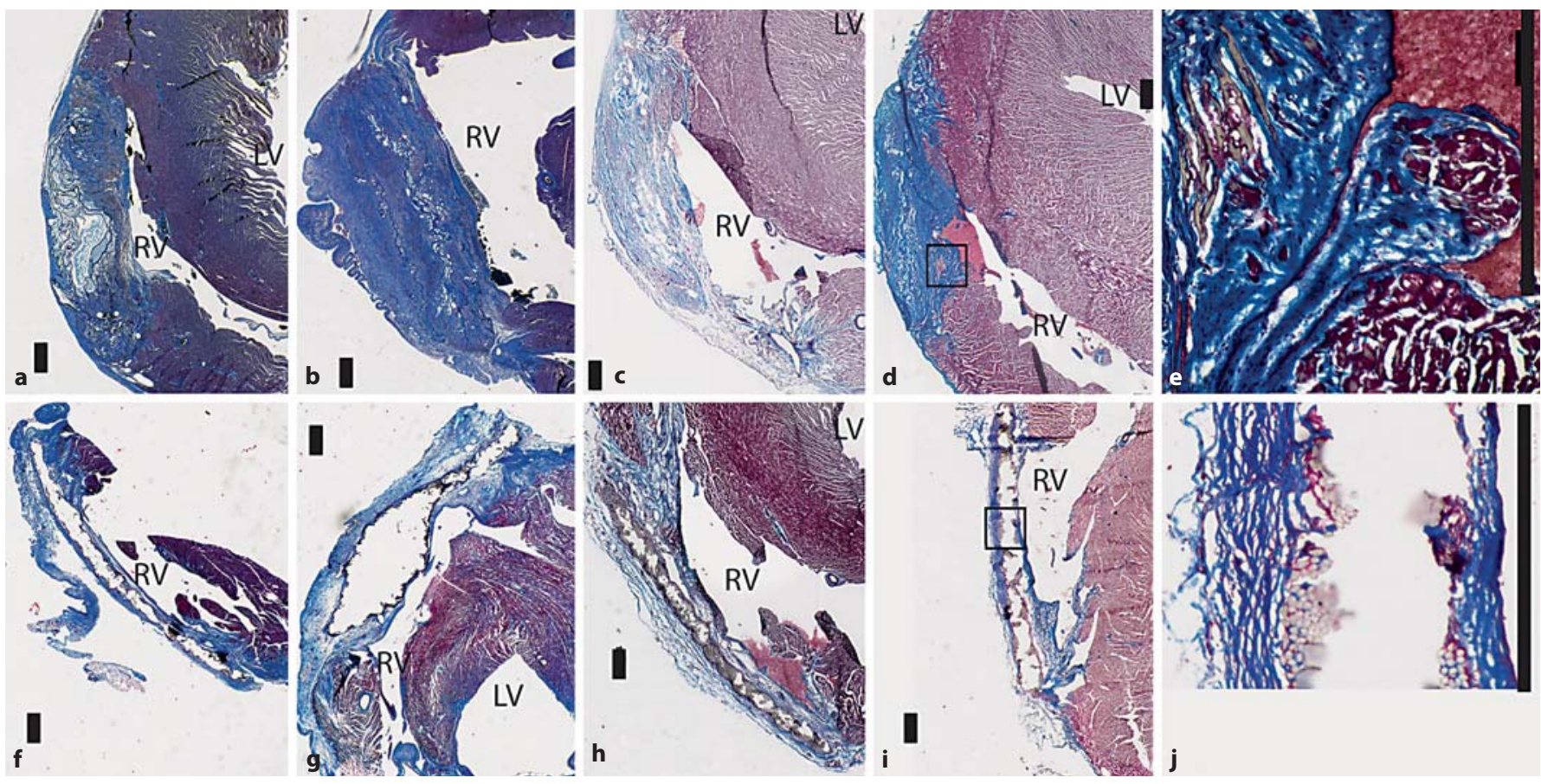

Fig. 3. Masson's trichrome C-ECM patch at 2, 4, 8, and 16 weeks postsurgery. The C-ECM patch recellularizes and remodels over 16 weeks whereas there are few changes in the Dacron-patched hearts over the 16 weeks. C-ECM at 2 (a), 4 (b), 8 (c), and 16 weeks (d). e C-ECM from the inset in d at 16 weeks. Dacron at 2 (f), $4(\mathbf{g}), 8$ (h), and 16 weeks (i). $\mathbf{j}$ Dacron from the inset in $\mathbf{i}$ at 16 weeks. Scale bar $=500 \mu \mathrm{m}$. RV and LV intracavitary spaces are labeled where appropriate.
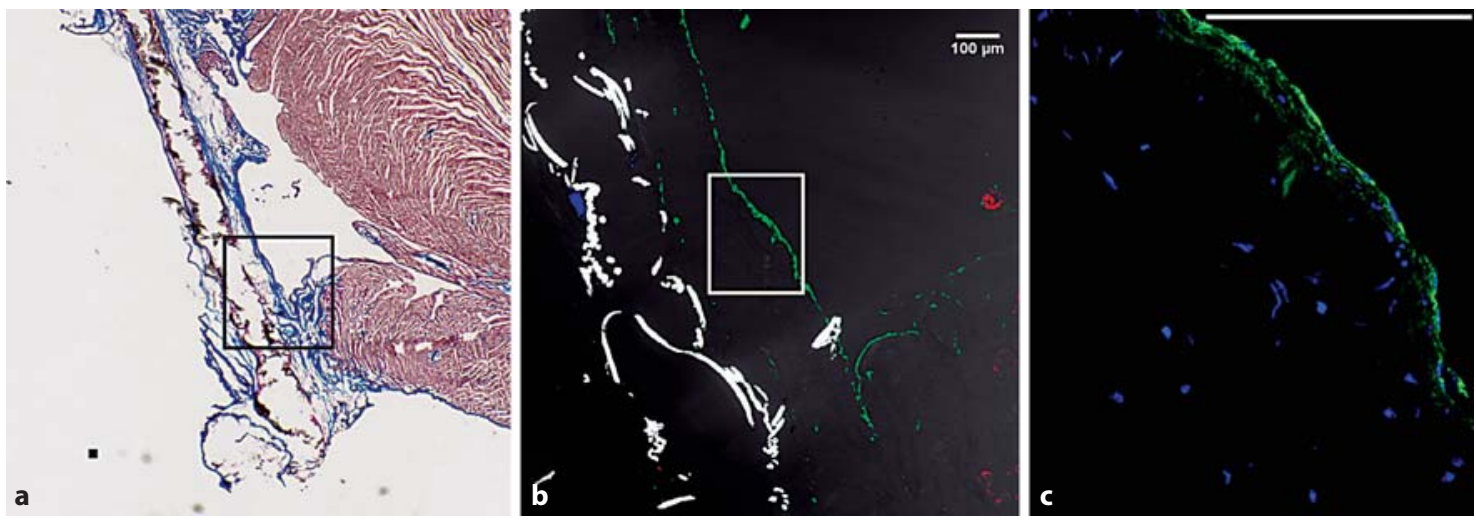

Fig. 4. Masson's trichrome and IF staining of the Dacron-patched area at 16 weeks showing little cellular infiltrate of the tissue surrounding the patch and no cellular infiltrate into the Dacron weave. There is an intact endothelium on the endocardial surface

smooth muscle cells within the connective tissue surrounding the Dacron patch (fig. 4) and no calcification was observed. The Dacron patch showed encapsulation by a thin dense connective tissue layer with few differences between 2 and 16 weeks postsurgery.

RVOT Repair with a Cardiac Biologic Scaffold but no cardiomyocytes surrounding patch. a $\times 2$, Masson's trichrome. $\mathbf{b} \times 10$ magnification with transmission light capture of the inset in a. $\mathbf{c} \times 60$ magnification of the inset in $\mathbf{b}$. $v W F=$ Green; $\alpha$-actinin $=$ red; DRAQ5 $=$ blue. Scale bar $=100 \mu \mathrm{m}$.

The C-ECM patch remodeled from an acellular collagen-rich scaffold material into densely cellular connective tissue. At 2 weeks, a portion of the original C-ECM patch could be identified in the Masson's trichrome-stained sections as denoted by the acellular area within the center of

Cells Tissues Organs 2012;195:159-170 

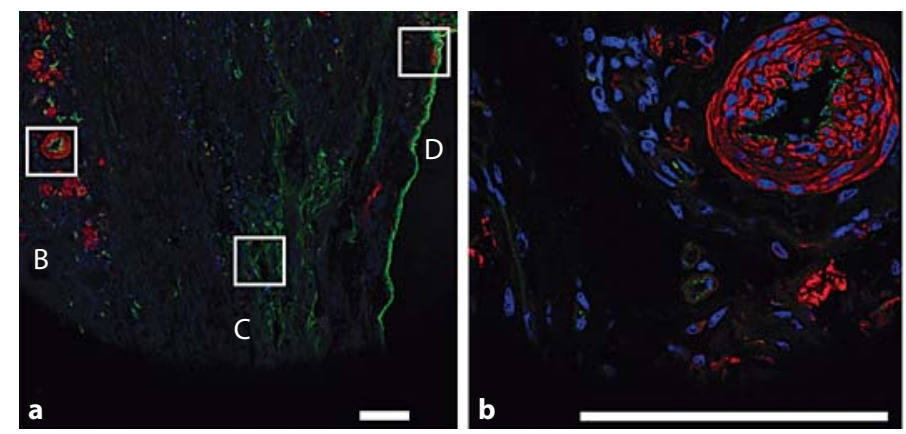

Fig. 5. IF staining of the remodeled C-ECM patch showing vWFpositive endothelium and vasculature and SMMHCII-positive smooth muscle throughout the middle of the patch at 16 weeks.
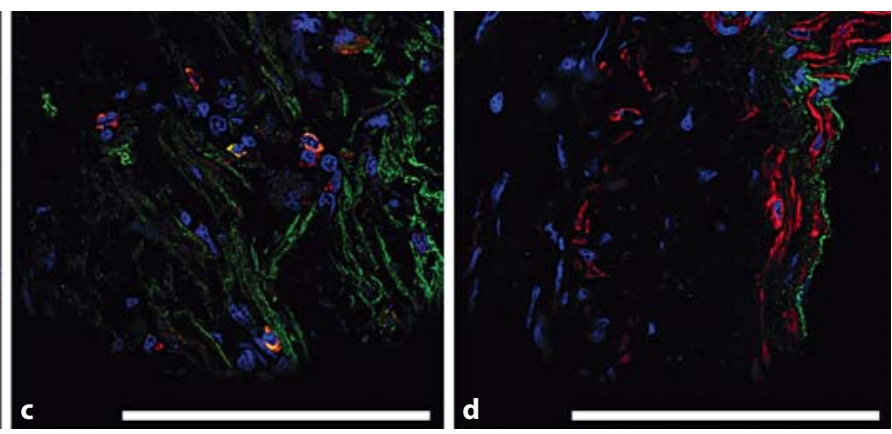

a $\times 10$. $\mathbf{b} \times 60$ magnification of inset $\mathbf{B}$ in $\mathbf{a} . \mathbf{c} \times 60$ magnification of inset $\mathbf{C}$ in $\mathbf{a}$. $\mathbf{d} \times 60$ magnification of inset $\mathbf{D}$ in $\mathbf{a}$. $\mathrm{vWF}=$ Green; SMMHCII $=$ red; DRAQ5 $=$ blue. Scale bar $=100 \mu \mathrm{m}$.
Fig. 6. IF staining of the remodeled CECM patch showing $\alpha$-actinin-positive cardiomyocytes in the middle of the patch on the epicardial surface at 16 weeks. $\alpha$ Actinin = Red; nuclei $=$ blue. $\mathbf{a} \times 10 . \mathbf{b} \times 40$ magnification of the inset in $\mathbf{a}$. Scale bar $=$ $100 \mu \mathrm{m}$.
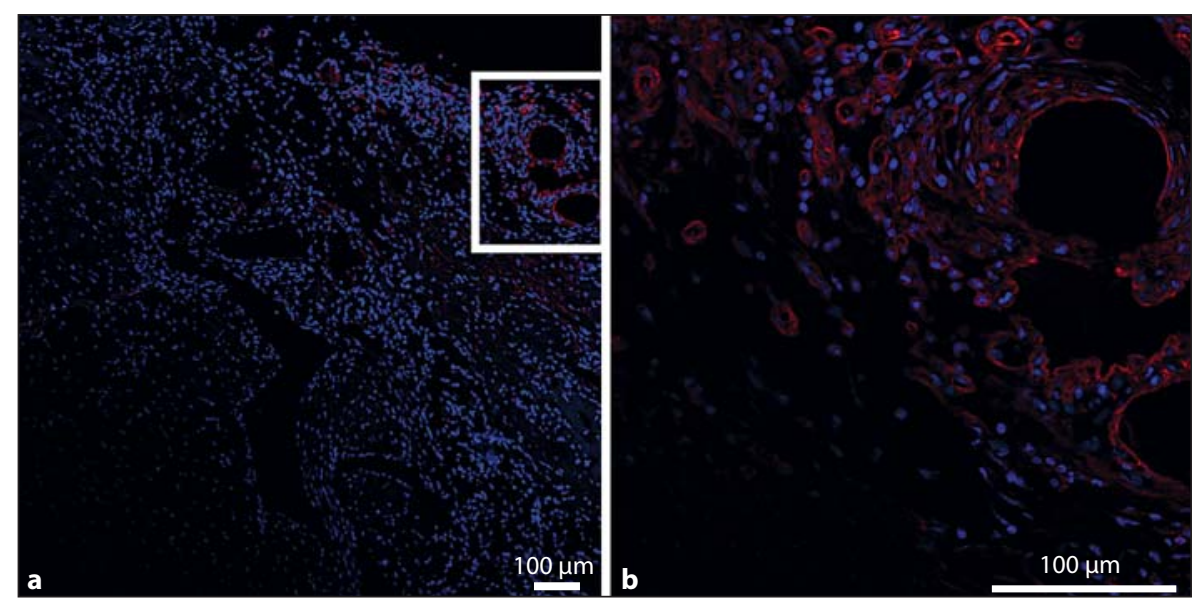

the patch. By 4 weeks, the C-ECM patch site consisted of densely cellular connective tissue. At 8 and 16 weeks, the trichrome images showed that the C-ECM patch had remodeled into vascularized collagenous tissue with small islands of striated muscle (fig. 3). von Kossa staining failed to show any signs of calcification. Staining for vWF showed a continuous endothelialized endocardium. Endothelial and smooth muscle cells were present throughout the patched regions either localized in the same area or independent from one another (fig. 5). There were small islands of cells which stained positive for $\alpha$-actinin, cardiac troponin $\mathrm{T}$, and connexin 43 both on the epicardium (fig. 6) and on the endocardium (fig. 7). These islands of cardiomyocytes also contained blood vessels as shown by the positive staining of SMMHC II and vWF (fig. 7). The results observed through IHC staining are preliminary in nature, however, as one sample per group was used for this analysis for the time points of 2, 4, and 8 weeks.

\section{Echocardiographic Assessment}

The RV minimum and maximum diameters were greater for the Dacron-patched hearts at 16 weeks compared to presurgery $(\mathrm{p}<0.05)$. At 16 weeks postsurgery, the RV minimum diameter was $150 \%$ greater than at presurgery, and the RV maximum diameter was $130 \%$ greater than the presurgeryvalues (fig. 8). The C-ECM-patched hearts at either time point showed no statistical differences in functional or dimensional measurements compared to presurgery values (fig. 8).

\section{Discussion}

A biologic scaffold composed of C-ECM was shown to be suitable as a replacement material for a full-thickness RVOT defect in this rat model. There was no morphologic evidence for persistence of the C-ECM, which ap- 
Fig. 7. IF staining of the remodeled CECM patch showing $\alpha$-actinin and cardiac troponin T-positive cardiomyocytes with connexin 43-labeled gap junctions, vWFlabeled endothelium, and SMMHCII-labeled smooth muscle in the middle of the patched area on the endocardial surface at 16 weeks. $\mathbf{a} \times 10$. vWF $=$ Green; $\alpha$-acti$\operatorname{nin}=$ red; DAPI $=$ blue. Scale bar $=200$ $\mu \mathrm{m}$. b-e Magnifications of the inset area on sequential slides. Scale bar $=50 \mu \mathrm{m}$. b $\times 63 . \alpha$-Actinin $=$ Green; cardiac tropo$\operatorname{nin} \mathrm{T}=$ red; DRAQ5 $=$ blue. $\mathrm{c} \times 60 . \mathrm{vWF}=$ Green; $\alpha$-actinin $=$ red; DAPI $=$ blue. d $\times 63$. Connexin $43=$ Green; $\alpha$-actinin $=$ red; DRAQ5 = blue. e $\times 60$. SMMHCII = Green; $\alpha$-actinin $=$ red; DAPI $=$ blue.
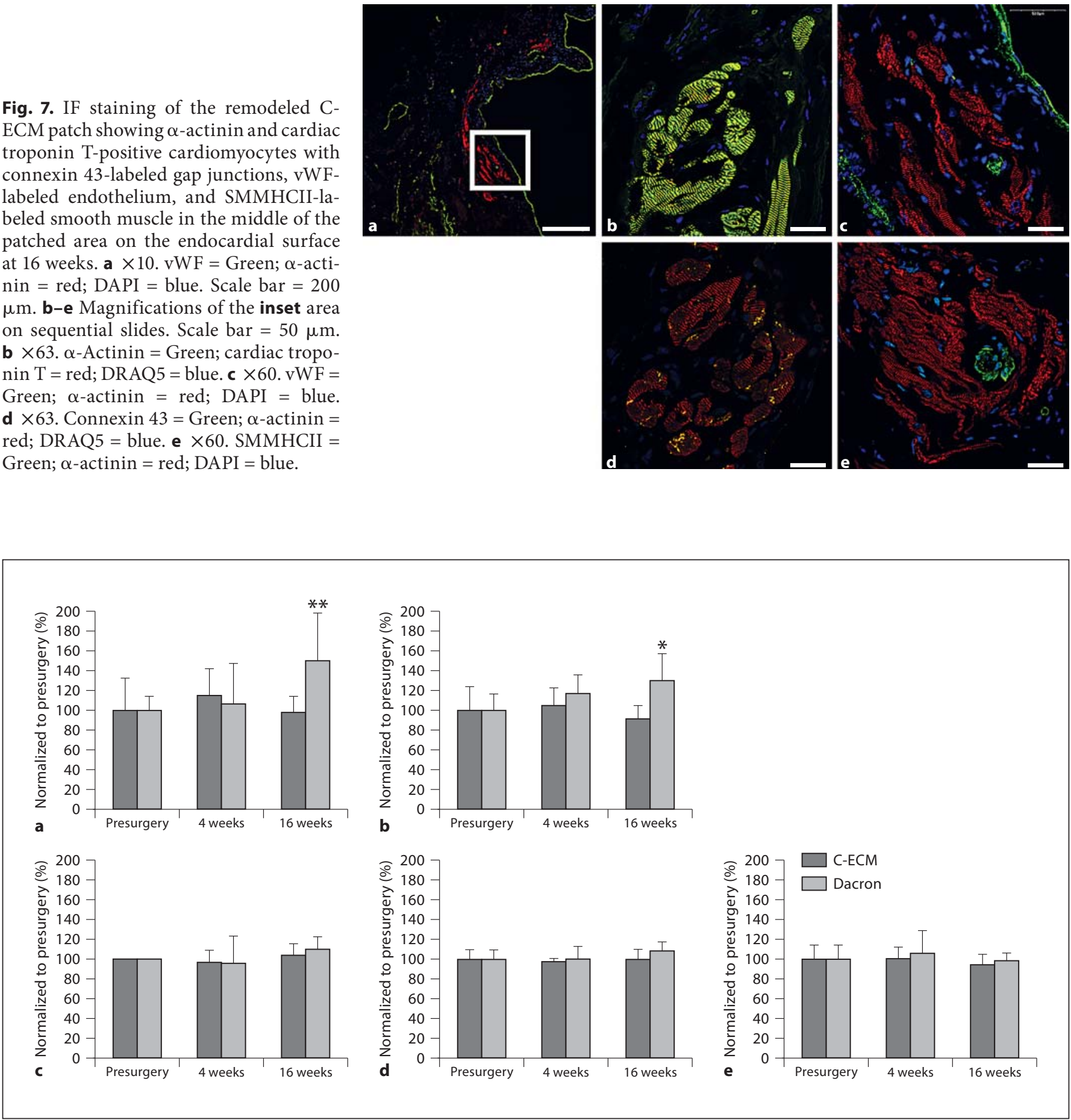

Fig. 8. Echocardiographic analysis at presurgery and 4 and 16 weeks postsurgery with one standard deviation. a RV minimum diameter. b RV maximum diameter. c LV minimum diameter. d LV maximum diameter. e LV fractional area shortening diameter. For the C-ECM patch, none of the measures were different from presurgery values at either 4 or 16 weeks. For the Dacron patch the RV minimum and maximum diameters had dilated by 16 weeks. ${ }^{*} \mathrm{p}<0.05$ compared to presurgery; ${ }^{* *} \mathrm{p}<0.05$ compared to presurgery and 4 weeks postsurgery. 
peared to have been completely degraded and replaced by host tissue that showed cardiac-specific markers at the periphery of the reconstructed area, including small islands of cardiomyocytes. By 16 weeks, the $2.5-\mathrm{mm}$-thick C-ECM patch had remodeled such that the thickness was similar to that of the native RVOT and the function and global dimensions of the heart were normal at 4 and 16 weeks postsurgery. In contrast, the Dacron material was surrounded by a dense fibrous capsule and the RV areas increased from the time of surgery until the time point of 16 weeks, indicating ventricular dilation. This difference may be partially attributed to differences in the mechanical properties of each patch material.

This is the first study reporting the use of cardiac-specific ECM to facilitate the constructive repair of a ventricular defect. Previous studies investigating the use of noncardiac ECM scaffolds for myocardial reconstruction have been associated with the presence of c-kit-positive cells, angiogenesis, small patches of cardiomyocytes, and partially organized collagenous connective tissue [Kochupura et al., 2005; Robinson et al., 2005; Ota et al., 2007; Kelly et al., 2009]. Ota et al. [2007] quantitatively analyzed the electrical activity of the patched area, whereas the present study qualitatively showed the presence of gap junctions within the small islands of cardiomyocytes. Kochupura et al. [2005] reported local contractility of the remodeled ECM scaffolds but the percentage of the patch on the free wall was only $5 \%$ so global measurements of ventricle function were of limited value [Pfeffer et al., 1979]. With the $25 \%$ (6 mm) replacement of the RV free wall, the present study was able to assess global dimensional and functional differences. The present study also had a longer end point than other degradable cardiac patch remodeling studies [Kochupura et al., 2005; Robinson et al., 2005; Badylak et al., 2006; Ota et al., 2007, 2008; Kelly et al., 2009], allowing assessment of longer-term maturation of the defect.

The cellular infiltrate and neovascularization that was observed in the remodeled C-ECM material is typical of the in vivo host response to non-cross-linked ECM biologic scaffold materials, such as small intestinal submucosa (SIS) and urinary bladder matrix (UBM) [Badylak et al., 2002; Gilbert et al., 2007; Brown et al., 2009]. Specifically, the C-ECM material showed a cellular infiltration, angiogenic response, and degradation rate similar to those for SIS and UBM and promoted the presence of siteappropriate cells. Angiogenesis is a common occurrence following ECM placement in many anatomic locations [Chen et al., 1999; Reddy et al., 2000; Kochupura et al., 2005; Thai et al., 2009; Zhao et al., 2010]. Singelyn et al.
[2009] showed migration of endothelial and smooth muscle cells toward C-ECM in the rat heart with increased arteriole formation, specifically with a gel form of CECM in a nondefect LV rat model. Zhao et al. [2010] recently described the time course of cellular infiltration in response to SIS particulate injection in an acute infarction with a reperfusion rat model. The cellular infiltration included initial migration of macrophages followed by myofibroblasts and angiogenesis. Suggested mechanisms of angiogenesis include: release of cytokines such as transforming growth factor- $\beta$ (TGF- $\beta$ ), basic fibroblast growth factor (b-FGF), vascular endothelial growth factor (VEGF), and stem cell factor [Voytik-Harbin et al., 1997; Hodde et al., 2001; McDevitt et al., 2003; Zhao et al., 2010]; chemoattractive properties of ECM degradation products to endothelial progenitor cells [Badylak et al., 2001; Li et al., 2004; Reing et al., 2009], and the suitability of the ECM as a substrate for endothelial cell attachment and proliferation [Badylak et al., 1999; Kalluri, 2003; Brown et al., 2006].

The remodeled C-ECM scaffold in the present study showed focal regions of cardiomyocytes along the edges of the repair site and across the endocardial and epicardial surfaces, suggesting that the presence of these cells was dependent upon a vascular supply and the proximity of healthy myocardium. The small islands of cardiomyocytes within the C-ECM-patched area lacked syncytium, representing immature myocardium that was not capable of actively contributing to cardiac function. Possible sources of the cardiomyocytes are resident islet1-positive (isl1+) [Laugwitz et al., 2005; Bu et al., 2009] cells or circulating bone marrow mesenchymal stem cells [Barile et al., 2011; Mangi et al., 2003; Zantop, 2006], both of which have been shown to form cardioblasts. The possibility also exists that iatrogenic effects caused a limited seeding of both patches but that the cardiomyocytes were only able to populate the C-ECM due to the presence of cell attachment sites and rapid angiogenesis. Further study is required to determine the origin of the cardiomyocytes and whether they would continue to mature into more functional myocardium with time.

The hearts repaired with the C-ECM patch had superior echocardiographic results compared to the hearts repaired with the Dacron patch. The Dacron RV minimum and maximum diameters increased in size by 16 weeks, which could be an early indication of aneurysm as the LV dimensions remained constant. There was no difference at the time point of 4 or 16 weeks for the C-ECM-patched heart, indicating that the patched area had constructively remodeled. The C-ECM patch did not adversely affect 
LV function and was not dilated; these measures are critical for an RVOT reconstruction patch. The improved echocardiographic findings of the C-ECM patch over the Dacron patch appeared to be related to the morphometric differences seen in the patched region.

Limitations of this study included the small animal model with one primary end point (i.e. 16 weeks) and that the source of the cells populating the patched region was not specifically determined. While the rats did increase their weight by about 25\%, a 6-month juvenile sheep model is the standard for CHD reconstruction due to calcification issues and growth rates similar to those of children [Hopkins et al., 2009]. The increase in weight observed was not indicative of structural and organ growth and was not expected to have a significant effect on final $\mathrm{RV}$ and LV volume measurements. Therefore, these measurements could be normalized to preoperative values for direct comparison. Only one animal was used for histologic evaluation at the early time points, which limited the analysis of cellular remodeling over time, but echocardiographic measurements enabled functional analysis of the tissue remodeling time course. A Dacron control was used in this study because of its current surgical use in cardiac and vascular tissue repair and its low thrombogenicity. Direct comparison of Dacron patches to CECM patches must account for differences in the initial thickness of the materials, which may contribute to final volumetric and dimensional differences in $\mathrm{RV}$ and $\mathrm{LV}$ structure.

While the findings of the present study are preliminary in nature, they show potential for the use of organspecific ECM in cardiac applications. This study does not explicitly show that C-ECM is better than ECM derived from other sources since head-to-head comparisons were not performed. However, the ECM of each tissue is synthesized by the resident cells and is in a state of dynamic reciprocity with these cells [Bissell et al., 1982; Nelson and Bissell, 2006]. Hepatocytes have shown superior structure and function when seeded upon liver-derived ECM scaffolds compared to ECM scaffolds derived from nonhepatic sources [Sellaro et al., 2007]. Hydrated decellularized tracheal matrix supported the formation of sitespecific epithelium and provided sufficient short-term mechanical integrity to withstand physiologic pressures [Remlinger et al., 2010]. Decellularized lung ECM provided signals for site-appropriate differentiation of mouse embryonic stem cells in the absence of other distinguishing cues [Cortiella et al., 2010]. Based on the tissue-specific structure and composition of C-ECM [Ott et al., 2008; Wainwright et al., 2010] and previous data showing advantages of tissue-specific ECM [Sellaro et al., 2007; Cortiella et al., 2010; Remlinger et al., 2010], it is logical that C-ECM would be a preferred scaffold material for myocardial reconstruction over ECM derived from nonhomologous sources. Reconstruction of the RVOT with a cardiac-derived ECM scaffold patch has not been evaluated prior to this study, but previous studies have used methods to engineer cardiac tissue before implantation. Sakai et al. [2001] used a 15-mm gelatin sponge that was preseeded with rat cardiomyocytes for 1-3 weeks and subsequently implanted. Similarly, Ozawa et al. [2004] used a caprolactone-based PCLA copolymer sponge seeded with smooth muscle cells. Each of these studies reported the ability of cell-seeded sponge materials to support the growth of fibrous tissue and the formation of an endothelial lining in the RVOT. However, there was little evidence that these scaffold materials were able to form functional tissue, and there was no analysis of ventricular function or dimensional changes.

Biodegradable polymer materials are used more commonly than cell-seeded sponges to repair damaged cardiac tissue and are a more attractive option. Yang et al. [2006] investigated a porous P4HB biodegradable synthetic patch material seeded with aortic cells. The study, however, was limited to 1 week in culture and did not perform any in vivo analysis of the material. Another study conducted by Kalfa et al. [2010] investigated a polydioxanone patch that was seeded with autologous mesenchymal stem cells in a growing lamb model. These patches were reported to display growth potential with less fibrosis and a more well-developed endothelial lining compared to a PTFE patch [Kalfa et al., 2010]. The results from each of these studies are also promising but lack a functional, global analysis of cardiac function after repair as well as confirmation of the presence of cardiacspecific cells.

The present study suggests that a biologic scaffoldbased approach, using a site-specific C-ECM material without the requirement of preseeding with cells, has potential for myocardial repair. The absence of a cellular component makes C-ECM an attractive option since the tissue repair patch can be easily produced and stored. A large majority of currently used cardiac patches are polymer-based scaffolds that are associated with a low rate of thrombogenicity, but these scaffolds lack growth potential and inevitably form fibrotic tissue when implanted. The use of an unseeded biodegradable PEUU patch to repair the RVOT was investigated by Fujimoto et al. [2007] with results similar to those from previous studies. The PEUU patch demonstrated the ability to form an en- 
dothelial lining but largely formed a fibrous encapsulation in the area. Fibroblast infiltration was observed; however, there was little evidence of constructive remodeling into cardiac-specific tissue, and ventricular functional analysis was not reported.

C-ECM produced by the described method possesses morphological advantages over current clinical materials for reconstructive surgeries due to the macroscopic and ultrastructural similarities to the region being replaced. For example, it may be possible to reconstruct the entire outflow tract, valve, and pulmonary artery from a decellularized intact porcine heart [Ott et al., 2008; Wainwright et al., 2010]. Furthermore, the advantageous mechanical behavior of the C-ECM relative to the normal heart [Wainwright et al., 2010] and subsequent remodeling could reduce the incidence of aneurysm formation [Breymann et al., 2009]. The use of decellularized xenogeneic tissue would also eliminate the current issues associated with homografts, specifically insufficient supply and limited size availability [Hickey et al., 2009; Konuma et al., 2009]. ECM scaffolds generally could eliminate issues of sensitization and rejection that are currently experienced with the use of homografts in pediatric patients, thereby increasing the potential for successful donor matching in a population that may require an orthotopic heart transplant [Rajani et al., 1998]. Numer- ous studies have shown the lack of an adverse immune response when an appropriately decellularized noncross-linked ECM biologic scaffold is placed within a xenogeneic recipient [Chen et al., 1999; Reddy et al., 2000; Brown et al., 2009; Daly et al., 2009]. Finally, it may be possible to use a 3-dimensional (3D) C-ECM patch seeded with stem cell-derived cardiomyocytes [Yang et al., 2008; Kamp and Lyons, 2009] to obtain an actively contracting patch as ECM in multiple in vitro investigations has been shown to support synchronously contractile cardiomyocytes [Ott et al., 2008; Eitan et al., 2010; Hata et al., 2010; Shah et al., 2010]. Additional studies are needed to assess the potential of C-ECM biologic scaffold material, but the possibility of using 3D C-ECM for the correction of $\mathrm{CHD}$ is promising.

\section{Acknowledgements}

The authors would like to gratefully acknowledge funding from the NIH [R03 EB009237-01 (T.W.G.) and T32 HL76124 (J.M.W.), NIH-NIBIB small research grant 1R03EB009237-01A1 (T.W.G.) entitled 'Cardiac Remodeling with Organ-Specific Extracellular Matrix Scaffolds', and NIH-NHLBI training grant (T32-HL76124) entitled 'Cardiovascular Bioengineering Training Program'].

\section{References}

Badylak, S.F., P.V. Kochupura, I.S. Cohen, S.V. Doronin, A.E. Saltman, T.W. Gilbert, D.J. Kelly, R.A. Ignotz, G.R. Gaudette (2006) The use of extracellular matrix as an inductive scaffold for the partial replacement of functional myocardium. Cell Transplant 15 (suppl 1): S29-S40.

Badylak, S.F., K. Kokini, B. Tullius, A. SimmonsByrd, R. Morff (2002) Morphologic study of small intestinal submucosa as a body wall repair device. J Surg Res 103: 190-202.

Badylak, S.F., A. Liang, R. Record, R. Tullius, J.P. Hodde (1999) Endothelial cell adherence to small intestinal submucosa: an acellular bioscaffold. Biomaterials 20: 2257-2263.

Badylak, S.F., K. Park, N. Peppas, G. McCabe, M. Yoder (2001) Marrow-derived cells populate scaffolds composed of xenogeneic extracel-
lular matrix. Exp Hematol 29: 1310-1318.

Badylak, S.F., D.A. Vorp, A.R. Spievack, A. Simmons-Byrd, J. Hanke, D.O. Freytes, A. Thapa, T.W. Gilbert, A. Nieponice (2005) Esophageal reconstruction with ECM and muscle tissue in a dog model. J Surg Res 128: 87-97.
Barile, L., F. Cerisoli, G. Frati, R. Gaetani, I. Chimenti, E. Forte, L. Cassinelli, L. Spinardi, C. Altomare, E. Kizana, A. Giacomello, E. Messina, S. Ottolenghi, M.C. Magli (2011) Bone marrow-derived cells can acquire cardiac stem cells properties in damaged heart. J Cell Mol Med 15: 63-71.

-Bissell, M.J., H.G. Hall, G. Parry (1982) How does the extracellular matrix direct gene expression? J Theor Biol 99: 31-68.

Breymann, T., U. Blanz, M.A. Wojtalik, W. Daenen, R. Hetzer, G. Sarris, G. Stellin, C. Planche, V. Tsang, N. Weissmann, D. Boethig (2009) European Contegra multicentre study: 7-year results after 165 valved bovine jugular vein graft implantations. Thorac Cardiovasc Surg 57: 257-269.

Brown, B.N., C.A. Barnes, R.T. Kasick, R. Michel, T.W. Gilbert, D. Beer-Stolz, D.G. Castner, B.D. Ratner, S.F. Badylak (2010) Surface characterization of extracellular matrix scaffolds. Biomaterials 31: 428-437.

Brown, B., K. Lindberg, J. Reing, D.B. Stolz, S.F. Badylak (2006) The basement membrane component of biologic scaffolds derived from extracellular matrix. Tissue Eng 12: 519-526.
Brown, B.N., J.E. Valentin, A.M. Stewart-Akers, G.P. McCabe, S.F. Badylak (2009) Macrophage phenotype and remodeling outcomes in response to biologic scaffolds with and without a cellular component. Biomaterials 30: 1482-1491.

Bu, L., X. Jiang, S. Martin-Puig, L. Caron, S. Zhu, Y. Shao, D.J. Roberts, P.L. Huang, I.J. Domian, K.R. Chien (2009) Human ISL1 heart progenitors generate diverse multipotent cardiovascular cell lineages. Nature 460: 113-117.

Chen, F., J.J. Yoo, A. Atala (1999) Acellular collagen matrix as a possible 'off the shelf' biomaterial for urethral repair. Urology 54: 407-410.

Cortiella, J., J. Niles, A. Cantu, A. Brettler, A. Pham, G. Vargas, S. Winston, J. Wang, S. Walls, J.E. Nichols (2010) Influence of acellular natural lung matrix on murine embryonic stem cell differentiation and tissue formation. Tissue Eng Part A 16: 2565-2580.

Crapo, P.M., T.W. Gilbert, S.F. Badylak (2011) An overview of tissue and whole organ decellularization processes. Biomaterials 32: 32333243. 
Daly, K.A., A.M. Stewart-Akers, H. Hara, M. Ezzelarab, C. Long, K. Cordero, S.A. Johnson, D. Ayares, D.K. Cooper, S.F. Badylak (2009) Effect of the alphaGal epitope on the response to small intestinal submucosa extracellular matrix in a nonhuman primate model. Tissue Eng Part A 15: 3877-3888.

-Eitan, Y., U. Sarig, N. Dahan, M. Machluf (2010) Acellular cardiac extracellular matrix as a scaffold for tissue engineering: in vitro cell support, remodeling, and biocompatibility. Tissue Eng Part C Methods 16: 671-683.

Freytes, D.O., R.M. Stoner, S.F. Badylak (2008) Uniaxial and biaxial properties of terminally sterilized porcine urinary bladder matrix scaffolds. J Biomed Mater Res B Appl Biomater 84: $408-414$.

-Freytes, D.O., R.S. Tullius, S.F. Badylak (2006) Effect of storage upon material properties of lyophilized porcine extracellular matrix derived from the urinary bladder. J Biomed Mater Res B Appl Biomater 78: 327-333.

Fujimoto, K.L., J. Guan, H. Oshima, T. Sakai, W.R. Wagner (2007) In vivo evaluation of a porous, elastic, biodegradable patch for reconstructive cardiac procedures. Ann Thorac Surg 83: 648-654.

Gilbert, T.W., J.M. Freund, S.F. Badylak (2009) Quantification of DNA in biologic scaffold materials. J Surg Res 152: 135-139.

-Gilbert, T.W., A. Nieponice, A.R. Spievack, J. Holcomb, S. Gilbert, S.F. Badylak (2008) Repair of the thoracic wall with an extracellular matrix scaffold in a canine model. J Surg Res 147: 61-67.

Gilbert, T.W., A.M. Stewart-Akers, A. SimmonsByrd, S.F. Badylak (2007) Degradation and remodeling of small intestinal submucosa in canine Achilles tendon repair. J Bone Joint Surg Am 89: 621-630.

-Hata, H., A. Bar, S. Dorfman, Z. Vukadinovic, Y. Sawa, A. Haverich, A. Hilfiker (2010) Engineering a novel three-dimensional contractile myocardial patch with cell sheets and decellularised matrix. Eur J Cardiothorac Surg 38: 450-455.

-Hickey, E.J., G. Veldtman, T.J. Bradley, A. Gengsakul, C. Manlhiot, W.G. Williams, G.D. Webb, B.W. McCrindle (2009) Late risk of outcomes for adults with repaired tetralogy of Fallot from an inception cohort spanning four decades. Eur J Cardiothorac Surg 35: 156-164, discussion 164.

Hodde, J.P., R.D. Record, H.A. Liang, S.F. Badylak (2001) Vascular endothelial growth factor in porcine-derived extracellular matrix. Endothelium 8: 11-24.

-Hopkins, R.A., A.L. Jones, L. Wolfinbarger, M.A. Moore, A.A. Bert, G.K. Lofland (2009) Decellularization reduces calcification while improving both durability and 1-year functional results of pulmonary homograft valves in juvenile sheep. J Thorac Cardiovasc Surg 137: 907-913, 913e1-e4.
Kalfa, D., A. Bel, A. Chen-Tournoux, A. Della Martina, P. Rochereau, C. Coz, V. Bellamy, M. Bensalah, V. Vanneaux, S. Lecourt, E. Mousseaux, P. Bruneval, J. Larghero, P. Menasche (2010) A polydioxanone electrospun valved patch to replace the right ventricular outflow tract in a growing lamb model. Biomaterials 31: 4056-4063.

Kalluri, R. (2003) Basement membranes: structure, assembly and role in tumour angiogenesis. Nat Rev Cancer 3: 422-433.

Kamp, T.J., G.E. Lyons (2009) On the road to iPS cell cardiovascular applications. Circ Res 105: 617-619.

Kelly, D.J., A.B. Rosen, A.J. Schuldt, P.V. Kochupura, S.V. Doronin, I.A. Potapova, E.U. Azeloglu, S.F. Badylak, P.R. Brink, I.S. Cohen, G.R. Gaudette (2009) Increased myocyte content and mechanical function within a tissue-engineered myocardial patch following implantation. Tissue Eng Part A 15: 2189-2201.

Kochupura, P.V., E.U. Azeloglu, D.J. Kelly, S.V. Doronin, S.F. Badylak, I.B. Krukenkamp, I.S. Cohen, G.R. Gaudette (2005) Tissue-engineered myocardial patch derived from extracellular matrix provides regional mechanical function. Circulation 112(suppl): I144-149.

Konuma, T., E.J. Devaney, E.L. Bove, S. Gelehrter, J.C. Hirsch, Z. Tavakkol, R.G. Ohye (2009) Performance of CryoValve SG decellularized pulmonary allografts compared with standard cryopreserved allografts. Ann Thorac Surg 88: 849-854, discussion 554-845.

Laugwitz, K.L., A. Moretti, J. Lam, P. Gruber, Y. Chen, S. Woodard, L.Z. Lin, C.L. Cai, M.M. Lu, M. Reth, O. Platoshyn, J.X. Yuan, S. Evans, K.R. Chien (2005) Postnatal isll+ cardioblasts enter fully differentiated cardiomyocyte lineages. Nature 433: 647-653.

Li, F., W. Li, S. Johnson, D. Ingram, M. Yoder, S.F. Badylak (2004) Low-molecular-weight peptides derived from extracellular matrix as chemoattractants for primary endothelial cells. Endothelium 11: 199-206.

Lloyd-Jones, D., R. Adams, M. Carnethon, G. De Simone, T.B. Ferguson, K. Flegal, E. Ford, K. Furie, A. Go, K. Greenlund, N. Haase, S. Hailpern, M. Ho, V. Howard, B. Kissela, S. Kittner, D. Lackland, L. Lisabeth, A. Marelli, M. McDermott, J. Meigs, D. Mozaffarian, G. Nichol, C. O'Donnell, V. Roger, W. Rosamond, R. Sacco, P. Sorlie, R. Stafford, J. Steinberger, T. Thom, S. WasserthielSmoller, N. Wong, J. Wylie-Rosett, Y. Hong (2009) Heart disease and stroke statistics 2009 update: a report from the American Heart Association Statistics Committee and Stroke Statistics Subcommittee. Circulation 119: e21-e181.

Mangi, A.A., N. Noiseux, D. Kong, H. He, M. Rezvani, J.S. Ingwall, V.J. Dzau (2003) Mesenchymal stem cells modified with Akt prevent remodeling and restore performance of infarcted hearts. Nat Med 9: 1195-1201.
McDevitt, C.A., G.M. Wildey, R.M. Cutrone (2003) Transforming growth factor-betal in a sterilized tissue derived from the pig small intestine submucosa. J Biomed Mater Res A 67: 637-640.

-Nelson, C.M., M.J. Bissell (2006) Of extracellular matrix, scaffolds, and signaling: tissue architecture regulates development, homeostasis, and cancer. Annu Rev Cell Dev Biol 22: 287309.

Ota, T., T.W. Gilbert, S.F. Badylak, D. Schwartzman, M.A. Zenati (2007) Electromechanical characterization of a tissue-engineered myocardial patch derived from extracellular matrix. J Thorac Cardiovasc Surg 133: 979-985.

Ota, T., T.W. Gilbert, D. Schwartzman, C.F. McTiernan, T. Kitajima, Y. Ito, Y. Sawa, S.F. Badylak, M.A. Zenati (2008) A fusion protein of hepatocyte growth factor enhances reconstruction of myocardium in a cardiac patch derived from porcine urinary bladder matrix. J Thorac Cardiovasc Surg 136: 13091317.

Ott, H.C., T.S. Matthiesen, S.K. Goh, L.D. Black, S.M. Kren, T.I. Netoff, D.A. Taylor (2008) Perfusion-decellularized matrix: using nature's platform to engineer a bioartificial heart. Nat Med 14: 213-221.

Ozawa, T., D.A. Mickle, R.D. Weisel, K. Matsubayashi, T. Fujii, P.W. Fedak, N. Koyama, Y. Ikada, R.K. Li (2004) Tissue-engineered grafts matured in the right ventricular outflow tract. Cell Transplant 13: 169-177.

$\checkmark$ Pfeffer, M.A., J.M. Pfeffer, M.C. Fishbein, P.J. Fletcher, J. Spadaro, R.A. Kloner, E. Braunwald (1979) Myocardial infarct size and ventricular function in rats. Circ Res 44: 503512 .

Rajani, B., R.B. Mee, N.B. Ratliff (1998) Evidence for rejection of homograft cardiac valves in infants. J Thorac Cardiovasc Surg 115: 111117.

Reddy, P.P., D.J. Barrieras, G. Wilson, D.J. Bagli, G.A. McLorie, A.E. Khoury, P.A. Merguerian (2000) Regeneration of functional bladder substitutes using large segment acellular matrix allografts in a porcine model. J Urol 164: 936-941.

Reing, J.E., L. Zhang, J. Myers-Irvin, K.E. Cordero, D.O. Freytes, E. Heber-Katz, K. Bedelbaeva, D. McIntosh, A. Dewilde, S.J. Braunhut, S.F. Badylak (2009) Degradation products of extracellular matrix affect cell migration and proliferation. Tissue Eng Part A 15: 605-614.

Remlinger, N.T., C.A. Czajka, M.E. Juhas, D.A. Vorp, D.B. Stolz, S.F. Badylak, S. Gilbert, T.W. Gilbert (2010) Hydrated xenogeneic decellularized tracheal matrix as a scaffold for tracheal reconstruction. Biomaterials 31: 3520-3526.

Robinson, K.A., J. Li, M. Mathison, A. Redkar, J. Cui, N.A. Chronos, R.G. Matheny, S.F. Badylak (2005) Extracellular matrix scaffold for cardiac repair. Circulation 112(suppl): I135I143.

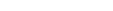

Cells Tissues Organs 2012;195:159-170 
Sakai, T., R.K. Li, R.D. Weisel, D.A. Mickle, E.T. Kim, Z.Q. Jia, T.M. Yau (2001) The fate of a tissue-engineered cardiac graft in the right ventricular outflow tract of the rat. J Thorac Cardiovasc Surg 121: 932-942.

Sellaro, T.L., A.K. Ravindra, D.B. Stolz, S.F. Badylak (2007) Maintenance of hepatic sinusoidal endothelial cell phenotype in vitro using organ-specific extracellular matrix scaffolds. Tissue Eng 13: 2301-2310.

-Shah, U., H. Bien, E. Entcheva (2010) Microtopographical effects of natural scaffolding on cardiomyocyte function and arrhythmogenesis. Acta Biomater 6: 3029-3034.

- Singelyn, J.M., J.A. DeQuach, S.B. Seif-Naraghi, R.B. Littlefield, P.J. Schup-Magoffin, K.L. Christman (2009) Naturally derived myocardial matrix as an injectable scaffold for cardiac tissue engineering. Biomaterials 30 : 5409-5416.
Sousa Uva, M., F. Lacour-Gayet, T. Komiya, A. Serraf, J. Bruniaux, A. Touchot, D. Roux, J. Petit, C. Planche (1994) Surgery for tetralogy of Fallot at less than six months of age. J Thorac Cardiovasc Surg 107: 1291-1300.

Thai, H.M., E. Juneman, J. Lancaster, T. Hagerty, R. Do, L. Castellano, R. Kellar, S. Williams, G. Sethi, M. Schmelz, M. Gaballa, S. Goldman (2009) Implantation of a three-dimensional fibroblast matrix improves left ventricular function and blood flow after acute myocardial infarction. Cell Transplant 18: 283-295.

Voytik-Harbin, S.L., A.O. Brightman, M.R. Kraine, B. Waisner, S.F. Badylak (1997) Identification of extractable growth factors from small intestinal submucosa. J Cell Biochem 67: 478-491.

Wainwright, J.M., C.A. Czajka, U.B. Patel, D.O. Freytes, K. Tobita, T.W. Gilbert, S.F. Badylak (2010) Preparation of cardiac extracellular matrix from an intact porcine heart. Tissue Eng Part C Methods 16: 525-532.

-Yang, C., R. Sodian, P. Fu, C. Luders, T. Lemke, J. Du, M. Hubler, Y. Weng, R. Meyer, R. Hetzer (2006) In vitro fabrication of a tissue engineered human cardiovascular patch for future use in cardiovascular surgery. Ann Thorac Surg 81: 57-63.
Yang, L., M.H. Soonpaa, E.D. Adler, T.K. Roepke, S.J. Kattman, M. Kennedy, E. Henckaerts, K. Bonham, G.W. Abbott, R.M. Linden, L.J. Field, G.M. Keller (2008) Human cardiovascular progenitor cells develop from a KDR+ embryonic-stem-cell-derived population. Nature 453: 524-528.

Zantop, T., T.W. Gilbert, M.C. Yoder, S.F. Badylak (2006) Extracellular matrix scaffolds are repopulated by bone marrow-derived cells in a mouse model of Achilles tendon reconstruction. J Orthop Res 24: 1299-1309.

Zhao, Z.Q., J.D. Puskas, D. Xu, N.P. Wang, M. Mosunjac, R.A. Guyton, J. Vinten-Johansen, R. Matheny (2010) Improvement in cardiac function with small intestine extracellular matrix is associated with recruitment of Ckit cells, myofibroblasts, and macrophages after myocardial infarction. J Am Coll Cardiol 55: 1250-1261. 